\title{
Corrosion and Protection of High Strength Low Alloy Steel in Oilfield Water Injection System
}

Fei Xie

College of Architecture and Transport and Storage; College of Petroleum Engineering

China University of Petroleum; Liaoning Shihua University

Qingdao, China,Fushun, China

xiefei0413@163.com

\author{
Dan Wang \\ College of Petroleum Engineering \\ Liaoning Shihua University \\ Fushun, China \\ wd841015@163.com
}

\author{
Ming $\mathrm{Wu}$ \\ College of Petroleum Engineering \\ Liaoning Shihua University \\ Fushun, China \\ wuming0413@163.com
}

\author{
Shixiang Song \\ College of Petroleum Engineering \\ Liaoning Shihua University \\ Fushun, China \\ Songshixiang.ssx@163.com
}

\begin{abstract}
There is serious scaling and corrosion in water injection line of Liaohe oil field. By analyzing water quality, it is learned that water quality of Liaohe oil field was alkaline, and its alkalinity was relatively high, containing much calcium ion, magnesium ion, chloride ion, sulfate ion, sulfate ion, saltness. The scales on the specimens of the water injection line mostly consists of calcium carbonate, with a little of sulfate scale and iron rust next. Based on simulation experiment, TH-7 was the most effective scale and corrosion inhibitor. When the concentration of TH-7 was $40 \mathrm{mg} / \mathrm{L}$, anti-scaling rate was $93.62 \%$, anti-corrosive rate was $92.86 \%$ and corrosion rate was $0.052 \mathrm{~mm} / \mathrm{a}$. Good results have been achieved in field application.
\end{abstract}

Keywords:high strength low alloy steel; scaling; corrosion; scale and corrosion inhibitor.

\section{INTRODUCTION}

Scaling and corrosion is one of the most serious problems in oil field water injection system [1.2]. In some areas of Liaohe oil field, serious scaling has emerged in the water injection line, injection well line and under the well. The brown and red powder-like deposit on the inner surface of water injection line and the light gray compact-sheet-like scale on the inner surface of injection well wall shorten the inner diameter of pipelines, reducing water flow section area, increasing water flow resistance and reducing transmission capacity. Black residua deposits on the bottom of water injection well, blocking injection pipe, increasing injection pressure and affecting water injection efficiency [3]. In addition, pipeline scaling causes serious corrosion beneath the scale. Scaling and corrosion cause a large number of pipelines to be useless [4]. As a result, the pipelines experience perforation many times, making pipelines disabled ahead of time and disrupting the normal production of oil field.

\section{SCALING AND CORROSION ANALYSIS OF WATER INJECTION LINE}

\section{A. Water Quality Analysis.}

There are two water resources in Liaohe oil field: one is underground water (clear water); the other is the refilling purified sewage from the oil field production. Sewage and clear water are mixed in production to be refilled. Water quality of Liaohe oil field was analyzed by the Sulin Classification [5].

According to Table 1, Liaohe oil field filling water quality belongs to $\mathrm{NaHCO}_{3}$ type, standing for good continental facies, closeness deposit environment, showing that water is alkalescent, and that $\mathrm{Ca}^{2+}, \mathrm{Mg}^{2+}$, salt concentration and total alkalinity are high, corrosive $\mathrm{Cl}^{-}$and $\mathrm{SO}_{4}{ }^{2-}$ content are rather high.

TABLE I. The RESUlts OF WATER SAMPLE ANALYSIS

\begin{tabular}{|c|c|c|c|c|c|c|c|c|c|}
\hline \multicolumn{9}{|c|}{ Water Quality Content $\left[\mathrm{mg} \cdot \mathrm{L}^{-1}\right]$} & \\
\hline $\mathrm{Na}^{+}$ & $\mathrm{Ca}^{2+}$ & $\mathrm{Mg}^{2+}$ & $B a^{2+}$ & $\mathrm{Fe}^{2+}$ & $C I^{-}$ & $\mathrm{SO}_{4}{ }^{2-}$ & $\mathrm{CO}_{3}{ }^{2-}+\mathrm{HCO}_{3}^{-}$ & Total Salt Content & \\
\hline 1400 & 30.8 & 7.3 & 2.5 & 3.5 & 1000 & 12 & 450 & 4000 & 8.2 \\
\hline
\end{tabular}

\section{B. Scaling Sample Analysis.}

By using XRD, scaling sample of Liaohe oil field filling pipelines is analyzed. According to Fig. 1, the scaling sample contains $\mathrm{CaCO}_{3}$, sulfate scale, carbonate scale and rusts such as $\mathrm{Fe}_{2} \mathrm{O}_{3}$.

Natural Science Foundation of China (50771053) 


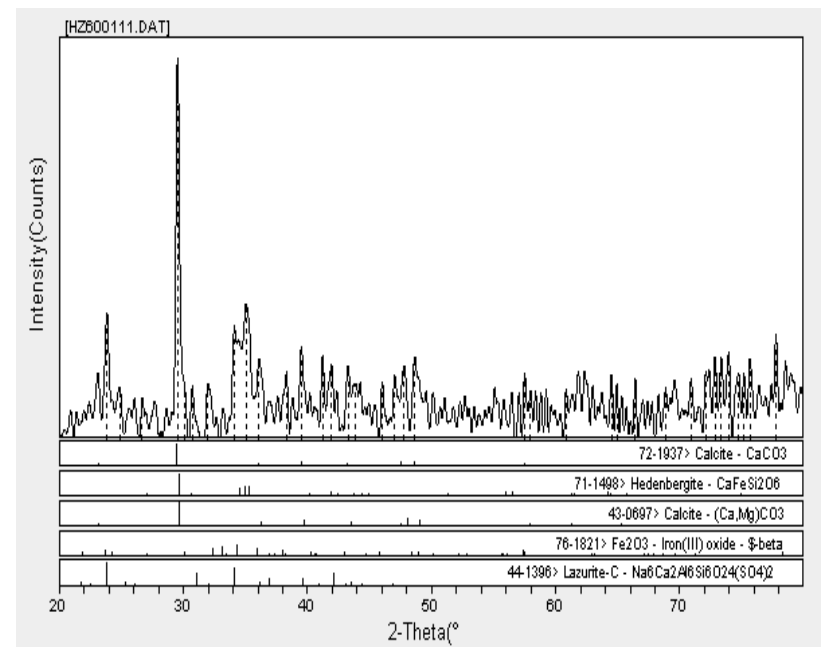

Figure 1. The results by XRD analysis

\section{The Mechanism of Scaling and Corrosion}

Scaling is the solid substance separated out from water on certain condition. It is usually low-solubility inorganic salt. There are several common scales, which are among the most harmful ones. They include carbonate scale(main content is $\mathrm{CaCO}_{3}$ ), sulfate scale(main contents are $\mathrm{CaSO}_{4}, \mathrm{BaSO}_{4}$, $\mathrm{SrSO}_{4}$, etc), iron compound scale(main content is $\mathrm{Fe}_{2} \mathrm{O}_{3}, \mathrm{FeO}$, $\left.\mathrm{Fe}(\mathrm{OH})_{2}, \mathrm{Fe}(\mathrm{OH})_{3}\right)$. Oil field stratum water contains plenty of $\mathrm{K}^{+}, \mathrm{Ca}^{2+}, \mathrm{Na}^{+}, \mathrm{Mg}^{2+}, \mathrm{Ba}^{2+}, \mathrm{Sr}^{2+}, \mathrm{Cl}^{-}, \mathrm{CO}_{3}{ }^{2-}, \mathrm{HCO}_{3}{ }^{-}, \mathrm{SO}_{4}{ }^{2-}$ and other ions. When water environment changes, the saturation balance of ions will be broken and inorganic salt scale will be produced.

\section{1) Mechanism of Scaling.}

In Liaohe oil field, the mixed filling of clear water and sewage is applied. The filling water has high dissolved solids and contains many kinds of ions. Different types of water, during the refilling process or mixing, would destabilize the once stable system and the deposits forms scales in the inner surface of pipelines because of the changes of environment condition temperature, pressure and so on. The equations of generating carbonate scale and sulfate scale are as follows [6.7]:

$$
\begin{aligned}
& \mathrm{Ca}^{2+}+\mathrm{CO}_{3}{ }^{2-} \rightarrow \mathrm{CaCO}_{3} \\
& \mathrm{Ca}^{2+}+2 \mathrm{HCO}_{3}^{-} \rightarrow \mathrm{CaCO}_{3}+\mathrm{CO}_{2} \uparrow+\mathrm{H}_{2} \mathrm{O} \\
& \mathrm{Mg}^{2+}+2 \mathrm{HCO}_{3}^{-} \rightarrow \mathrm{MgCO}_{3}+\mathrm{CO}_{2} \uparrow+\mathrm{H}_{2} \mathrm{O} \\
& \mathrm{Ca}^{2+}+\mathrm{SO}_{4}{ }^{2-} \rightarrow \mathrm{CaSO}_{4}
\end{aligned}
$$

Usually most oil field stratum water contains no or very little $\mathrm{CO}_{3}{ }^{2-}$, whereas $\mathrm{HCO}_{3}{ }^{-}$accounts for the main part. Therefore, (2) and (3) is more representative to indicate the reaction of carbonate deposit.

\section{2) Mechanism of Corrosion Beneath Scaling.}

Layers of scales deposit on the inner surface of filling pipelines. The tiny bore on the layers of scales would be the material passage for the corrosion reaction to cause corrosion beneath scale. When part of pipeline inner surface is covered with scales, relative closed micro-environment will be available It is very hard for oxygen to pass the layers of scales and enter the metal interface beneath the layers of scales. Therefore, with the process of corrosion reaction, layers of scales become oxygen poor area. This area, with other areas of external layers of scales, will form oxygen concentration cell. Usually corrosion layers have selective of negative ions. And metal positive ions could hardly diffuse outside. Thus with the accumulation of $\mathrm{Fe}^{2+}$, positive charges are surplus to lead external Cl- to the inner for the balance of charge. Hydrolyzation of metal chloride will acidify the environment beneath layers of scales, speeding up the corrosion beneath layers of scales. The block system autocatalytic mechanism is same as crevice corrosion [8].

\section{Preventive Measure}

The compound medicament composed of polyphosphate, organic phosphate, zinc salts and polymer dispersants was adopted for this experiment [9.10]. Thereinto, polyphosphate and zinc salts belong to cathode inhibitor and could deposit on the metal surface to hold back the corrosion on the metal surface. organic phosphate, by complexing solubilization, low dose effect and other mechanisms, to prevent the scaling ions from being separated out and depositing on the surface of the equipment; the main function of polymer dispersant is to diffuse dirt particle and stop the formation of scales. Compare three compound medicaments of FE-3, TH-6, TH-7 and select the best scale and corrosion inhibitor.

\section{A. Experiment Method.}

As for the experiment, Petroleum and Natural gas industry standard SY/T 5673-93(oilfield scale inhibitor performance evaluation method) and SY/T 5273-91(oilfield water injection corrosion inhibitor evaluation method) were applied. The $20 \mathrm{G}$ steel pieces $(50 \times 25 \times 2 \mathrm{~mm})$ which have been rinsed with ethanol and acetone were put into the scale inhibitor-filled corrosive liquid and the no- scale inhibitor-filled corrosive liquid respectively, and they are immersed at $60^{\circ} \mathrm{C}$ for 72 hours. Then they are taken out and dried and weighed. Anti-scaling rate and corrosion rate are calculated according to the steel piece weightlessness of pre-and postal corrosion and the quality of steel pieces before corrosion. The three compound medicaments of FE-3, TH-6 and TH-7 was experimented when the concentration is $10 \mathrm{mg} / \mathrm{L}$. Then choose the medicament with the optimal scale and corrosion inhibiting rate, the smallest corrosion rate. Then the chosen scale and corrosion inhibitor was experimented when the concentration is $20 \mathrm{mg} / \mathrm{L}, 30 \mathrm{mg} / \mathrm{L}, 40 \mathrm{mg} / \mathrm{L}$ and $50 \mathrm{mg} / \mathrm{L}$.

\section{B. Results of the Experiment.}

Fig. 2 shows that the anti-scaling rate and anti-corrosive rate increase remarkably while the corrosion rate slow down from the no-medicament solution to TH-7. In addition, Fig. 3shows the same result as Fig. 2 which means TH-7 is the best medicament for scaling prevention and corrosion tardiness. Furthermore TH-7 is the suitable scale and corrosion inhibitor for Liaohe oil field. 


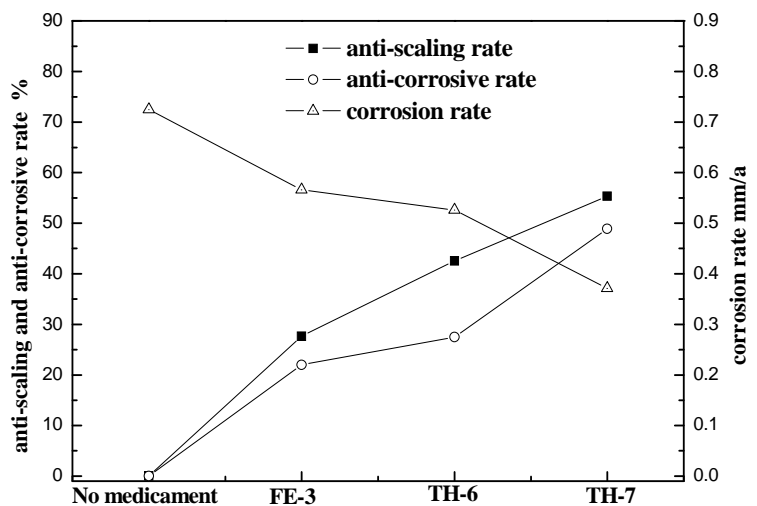

Figure 2. The anti-scaling rate, anti-corrosive rate and corrosion rate at different medicaments

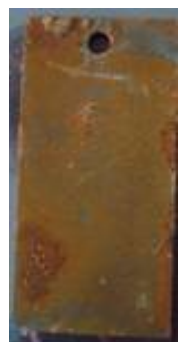

(a)

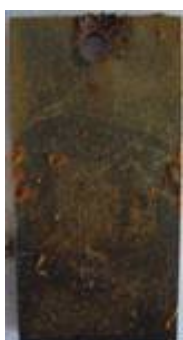

(b)

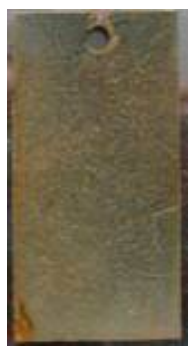

(c)

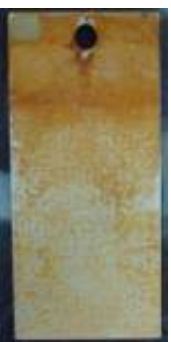

(d)
Figure 3. The Macro morphology of samples at $10 \mathrm{mg} / \mathrm{L}$ in different solutions: no medicament(a), FE-3 (b), TH-6(c), TH-7(d)

Fig. 4 and Fig. 5 show the concentration of the medicament increases from $20 \mathrm{mg} / \mathrm{L}$ to $40 \mathrm{mg} / \mathrm{L}$. The anti-scaling rate and anti-corrosive rate increase fast at first and slow down afterwards. The concentration between $40-50 \mathrm{mg} / \mathrm{L}$ is the best recipe for both economic aspect and corrosion prevention aspect. TH-7 not only meets the requirements of petrochemical industry, but also meets the economical requirement. It can prevent the scaling and corrosion in sewage system.

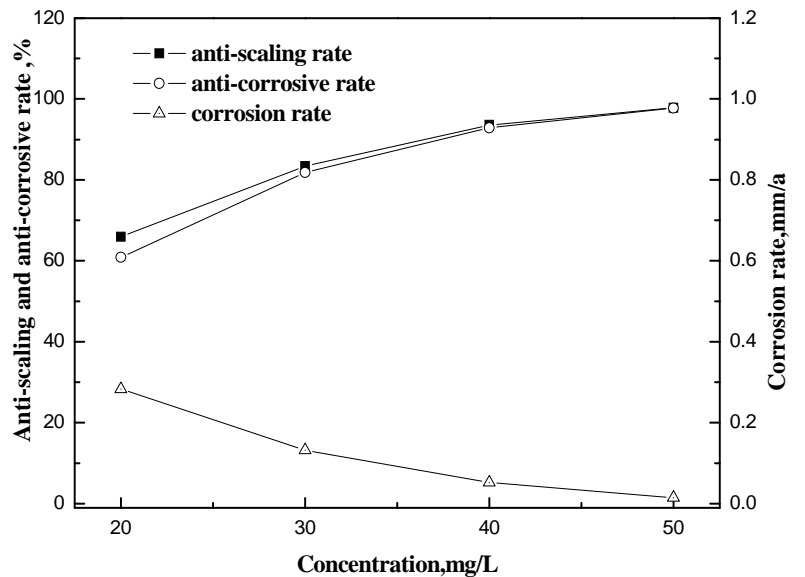

Figure 4. The anti-scaling rate, anti-corrosive rate and corrosion rate of $\mathrm{TH}-$ 7 at different concentration

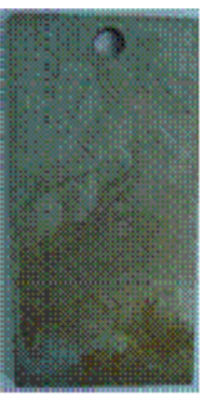

(a)

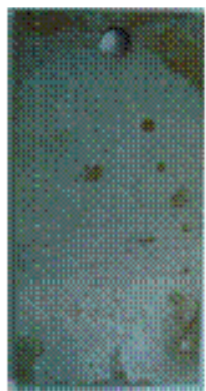

(b)

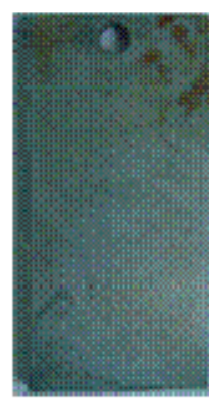

(c)

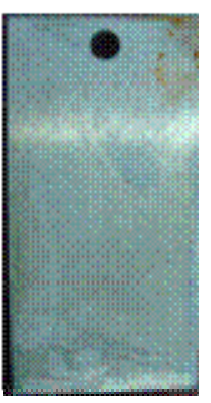

(d)
Figure 5. The samples of TH-7 solution at different concentration: $20 \mathrm{mg} / \mathrm{L}(\mathrm{a}), 30 \mathrm{mg} / \mathrm{L}(\mathrm{b}), 40 \mathrm{mg} / \mathrm{L}(\mathrm{c}), 50 \mathrm{mg} / \mathrm{L}(\mathrm{d})$

\section{ON SITE EXPERIMENT}

\section{A. Experimental method.}

On site experiment is held in the sewage treatment room in Gao'Er Lian factory. Two reserved valves of drain pipeline and bypass line are used to connect with the experiment pipeline whose material is identical with the material of the sewage reinjection system. The temperature of the experimental sewage is controlled at $60^{\circ} \mathrm{C}$ and flow rate is at $150 \mathrm{~m}^{3} /$ day by installing valves on the flowmeter. Give medicament treatment to the bypass line by using the $\mathrm{TH}-7$ (concentration $45 \mathrm{mg} / \mathrm{L}$ ). Evaluate the best composition of the on-site experiment result by analyzing the corrosion and scaling the comparative pipelines.

\section{B. Experimental result.}

Fig. 6 shows that TH-7 works well in the on-site experiment. The corrosion rate reduces from $0.81 \mathrm{~mm} / \mathrm{a}$ to $0.05 \mathrm{~mm} / \mathrm{a}$. The anti-scaling rate and anti-corrosive rate are both above $90 \%$ which is identical with the experiment result.

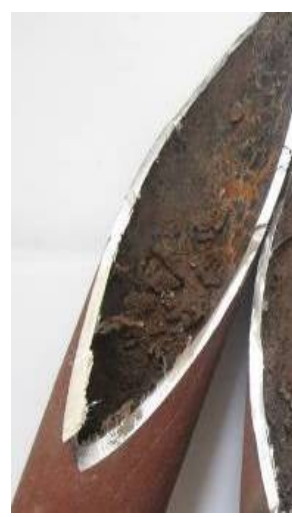

(a) (b)

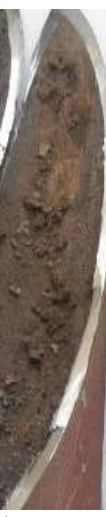

)

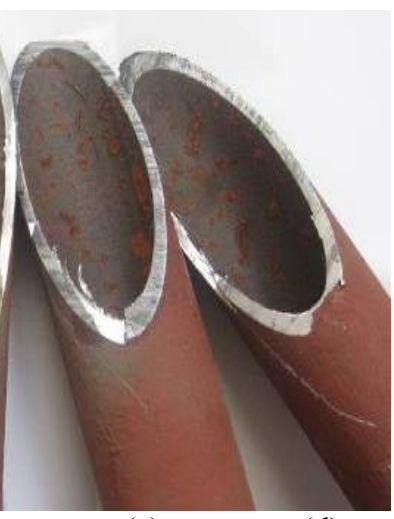

(c) (d)
Figure6. The contrast about before and after medicament: before medicament (a) and (b), after medicament (c) and (d)

\section{CONCLUSIONS}

- The water quality of Liaohe oil field is $\mathrm{NaHCO}_{3}$ type which is alkaline. High level of $\mathrm{Ca}^{2+}, \mathrm{Mg}^{2+}$, salt and alkali, $\mathrm{Cl}^{-}$and $\mathrm{SO}_{4}{ }^{2-}$. 
- The on-site sample of the scale mainly contains $\mathrm{CaCO}_{3}$, sulfate scale, carbonate scale and $\mathrm{Fe}_{2} \mathrm{O}_{3}$ etc.

- The clear and sewage water, which cause the sediment, are used by the oil field. The sediment scales on the surface of the pipelines. The corrosion by the scaling is called block system autocatalysis which is the same as the development of the crevice corrosion.

- TH-7 is suitable for the water of Liaohe oil field and the result of using it is remarkable on site. When the concentration is $40 \mathrm{mg} / \mathrm{L}$, the anti-scaling rate is $93.62 \%$, anti-corrosive rate is $92.86 \%$ and the corrosion rate is $0.052 \mathrm{~mm} / \mathrm{a}$. The result shows that TH-7 meets the requirements of petrochemical industry. The concentration between $40-50 \mathrm{mg} / \mathrm{L}$ is the best recipe.

\section{REFERENCES}

[1] Y.X. Yang and X.J. Zhang, "Status and Problems of Sewage Treatment Technology about China's Major Oilfields," Oil \& Gas Surface Engineering, Vol.. 20, pp. 4-5, January 2001.

[2] B.Q. Ma, Oilfield Chemical Theory and Technology. Beijing: Petroleum Industry Press, 1995, pp.56-59

[3] B.G. Li, L.L. Qi and Y.C. Li, Petrochemical Industrial Water Treatment Technology. Beijing : China Petrochemical Press, 1999, pp.132-140

[4] L.M. Zhang, S.W. Liu and B.S. Chen, "The Research and Application of Scaling and Corrosion Inhibitor on Oil Wells," Oil \& Gas Surface Engineering, Vol.. 20, pp. 69-70, April 2001

[5] C.L. Zhao and Y.W. Wang, "Formation Water Type Analysis of Shishugou Group in Cainan Oilfield," Pilot Production Technology, Vol. 27, pp. 25-26, March 2006

[6] Z.L. Xiao, C.S. Pu and Y. Shi, "The Progress of Inorganic Scaling and Prediction in Oilfield Water," Fault-Block Oil \& Gas Field, Vol. 11, pp. 76-78, 2004.

[7] Z. Peng, "Study on Scaling Mechanism and Prevention of Oil Wells," Inner Mongolia Petrochemical Industry, Vol. 4, pp. 16-19, 2009.

[8] X.G. Li, X.P. Guo and Y.D. He, Material Corrosion and Protection. Changsha: Central South University Press, 2009, pp.91-93.

[9] Z. Lu, Oilfield water treatment technology. Beijing: Petroleum Industry Press, 1990, pp.121-125.

[10] F.L. Zhao, Oil Extraction Chemical. Shandong: Petroleum University Press, 1997, pp.39-43. 